\title{
Effects of the Recess Geometry on Flow Characteristics of Cryogenic Hybrid Journal Bearings for Rocket Turbopumps
}

\author{
Mamoru Oike ${ }^{1)^{*}}$, Masataka Kikuchi ${ }^{2)}$, Satoshi Takada ${ }^{2)}$, Takayuki Sudo ${ }^{2)}$ and Tomoyuki Takano ${ }^{3)}$ \\ ${ }^{1)}$ Department of Mechanical Engineering, Ishinomaki Senshu University, 1 Shinmito, Minamisakai, Ishinomaki, Miyagi 986-8580, Japan \\ ${ }^{2)}$ Kakuda Space Center, Japan Aerospace Exploration Agency, 1 Koganezawa, Kimigaya, Kakuda, Miyagi 981-1525, Japan \\ ${ }^{3)}$ Japan Aerospace Technology, 1 Koganezawa, Kimigaya, Kakuda, Miyagi 981-1525, Japan \\ *Corresponding author: Mamoru Oike (oike@isenshu-u.ac.jp)
}

Manuscript received 27 January 2018; accepted 24 April 2018; published 15 July 2018

Presented at the 6th World Tribology Congress 2017 Beijing, September 2017

\begin{abstract}
In the present study, a flow visualization experiment in the clearance between a clear floating-ring and a rotating journal was carried out in order to clarify the effects of the recess geometry on the flow characteristics. Five types of the floating-rings with different recess geometries, i.e., the plane rhombus, the plane circle, the revise circular Young Leaf Mark, the dome and the revise dome geometries, were operated at a rotational speed of up to $40,000 \mathrm{rpm}$ using liquid nitrogen as the working fluid to observe the interaction between source flow from the recess and rotating flow induced by the journal rotation in the clearance. The cavitation cloud inside the clearance was induced by viscous frictional heating and the pressure drop. The influence of the sweepback angle $\left(\theta_{s}\right)$ of the recess leading edge on the flow characteristics was investigated by comparing flow coefficient $\left(C_{f}\right)$ and the cavitation cloud area ratio $(A c)$ obtained from the visual image. Based on the experimental results, it may be confirmed that the effects of the recess geometry on the flow characteristics of the cryogenic hybrid journal bearings are mainly caused by the influence of the $\theta_{s}$ value on the flow condition.
\end{abstract}

\section{Keywords}

journal bearing, cryogenic turbopump, flow visualization, recess geometry, recess sweepback angle, cavitating flow, liquid nitrogen

\section{Introduction}

The lifetime of a rocket engine depends mainly on the durability of bearings and seals in a cryogenic turbopump. Almost all cryogenic turbopumps of rocket engines have a rotor system supported by self-lubricating ball bearings operated in liquid hydrogen or liquid oxygen. Since a differential slip and Hertz stress act in the rolling contact area between a ball and a raceway, it is difficult to avoid the lifetime shortening wear of material inside the contact area. Moreover, the polytetrafluoroethylene (PTFE) solid lubricant film on the contact area has a limitation of the $S V$ value, which is the value of Hertzian stress $(S)$ times the differential slip speed $(V)$, to maintain a good lubricating condition in the cryogenic fluid [1]. Therefore, the rotational speed of the cryogenic turbopump must be restricted to avoid critical damage such as seizing. A hybrid journal bearing $(\mathrm{HJB})$ is a fluid-film journal bearing with characteristics of both hydrostatic and hydrodynamic bearings. The main advantage of HJBs are small size, good load capacity, a quasi-unlimited life (no observed wear), and the use of process fluid for lubrication [2]. By replacement of the self-lubricating ball bearings in the cryogenic turbopumps by HJBs, a significantly higher lifetime can be obtained and the inherent limitation of the rotational speed of the turbopumps can be greatly extended in cryogenic rocket engines for future reusable launch vehicles (RLVs), where the lifetime of mechanical components is a critical issue. Although many experimental studies on HJBs have been carried out to develop high performance HJBs for cryogenic turbopumps [3-7], it has not yet been completely realized because there is little demand for development of a launch vehicle capable of being reused over hundred times. However, detailed reference data based on experimental results will be required to develop high performance cryogenic HJBs in the near future.

In a previous study [8], two types of hybrid journal bearings (HJBs) with different recess geometries, i.e., the Young Leaf Mark (YLM, Types Ca and D in Fig. 1) and the square (Type $\mathrm{Ba}$ ), were operated at a rotational speed of up to $67,000 \mathrm{rpm}$ using liquid nitrogen as the working fluid in order to clarify the influences of the journal rotating direction on performance of the cryogenic HJBs. The dependence of the rotor vibration on the rotational speed was confirmed to be affected by the 

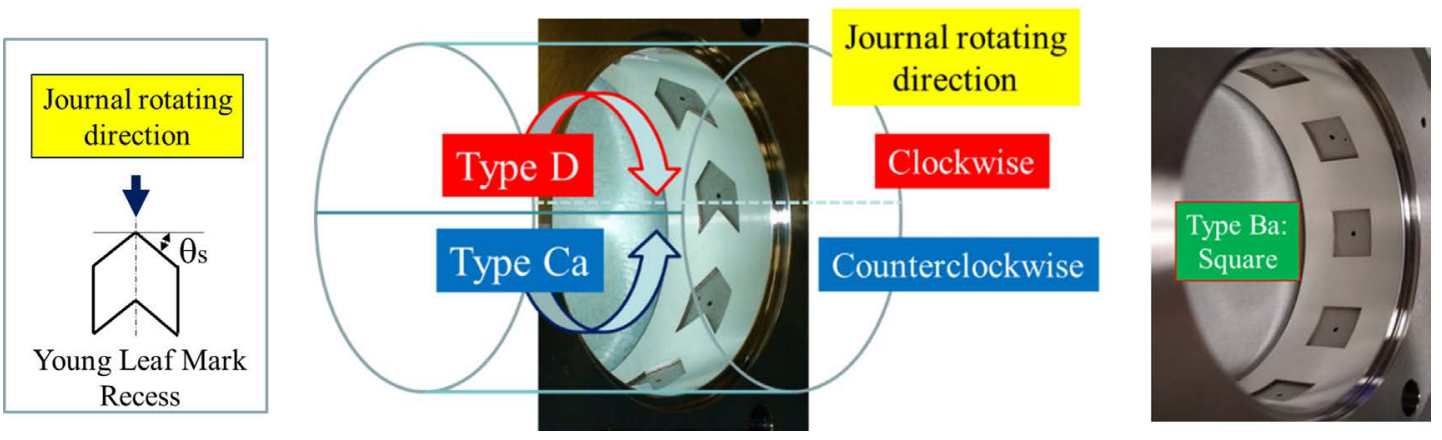

Fig. 1 Photos of test HJB inner surfaces with Young Leaf Mark recess (Journal rotating direction: counterclockwise for Type Ca, $\theta_{s}=-45$ deg., clockwise for Type $\mathrm{D}, \theta_{s}=45 \mathrm{deg}$.) and square recess (Type $\mathrm{Ba}, \theta_{s}=0 \mathrm{deg}$. ) [8]

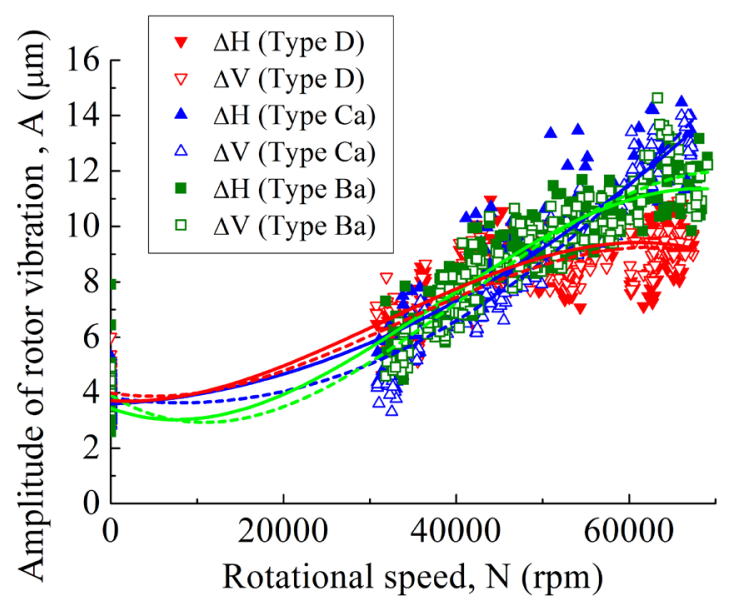

Fig. 2 Comparisons of the horizontal and vertical amplitudes $(\Delta H$ and $\Delta V$ ) of the rotor vibration for Types $\mathrm{D}, \mathrm{Ca}$ and Ba of HJBs [8]

direction of journal rotation. As shown in Fig. 2, the test HJB (Type D) with the positive sweepback angle $\left(\theta_{s}\right)$ of the recess leading edge showed the smallest rotor vibration in the highrotational-speed operation where the hydrodynamic effect was predominant. A flow visualization experiment in the clearance between a clear floating-ring (CFR) and a rotating journal was carried out to clarify the effect of the $\theta_{s}$ value on the flow characteristics. Four types of CFR with different recess geometries, i.e., the YLM (Type D), the revise YLM (Type C), the square (Type B) and the non-recessed (Type FR) geometries, were operated at a rotational speed of up to $45,000 \mathrm{rpm}$ using liquid nitrogen $\left(\mathrm{LN}_{2}\right)$ to observe the interaction between a source flow from the recess and rotating flow induced by the journal rotation in the clearance [9]. The dependence of the flow characteristics on the rotational speed was confirmed to be affected by the $\theta_{s}$ value.

In the present study, five types of the CFR with different recess geometries, i.e., the plane rhombus, the plane circle, the circular Young Leaf Mark, the dome and the revise dome geometries, were newly operated at a rotational speed of up to $40,000 \mathrm{rpm}$ using liquid nitrogen as the working fluid to compare with the results obtained for Types B, C, D and FR in the previous study [9]. The effects of the recess geometry on the flow characteristics were investigated by comparing the flow coefficient $\left(C_{f}\right)$ and the cavitation cloud area ratio $(A c)$ obtained from the visual image.

\section{Experimental procedure}

2.1 Clear floating-ring

Flow visualization experiments were conducted to clarify the flow pattern of cryogenic fluid within the clearance between the CFR and the journal. Figure 3 is a photograph of the test CFR (Type D) section [9]. The test CFR made of polycarbonate is a floating-ring which has four orifice-compensated recesses on the inner surface to simulate the interaction between a source flow from the recess and a rotating flow induced by the journal rotation in the clearance of the HJB, as shown in Fig. 3. Five types of the CFRs have different recess geometries, i.e., the

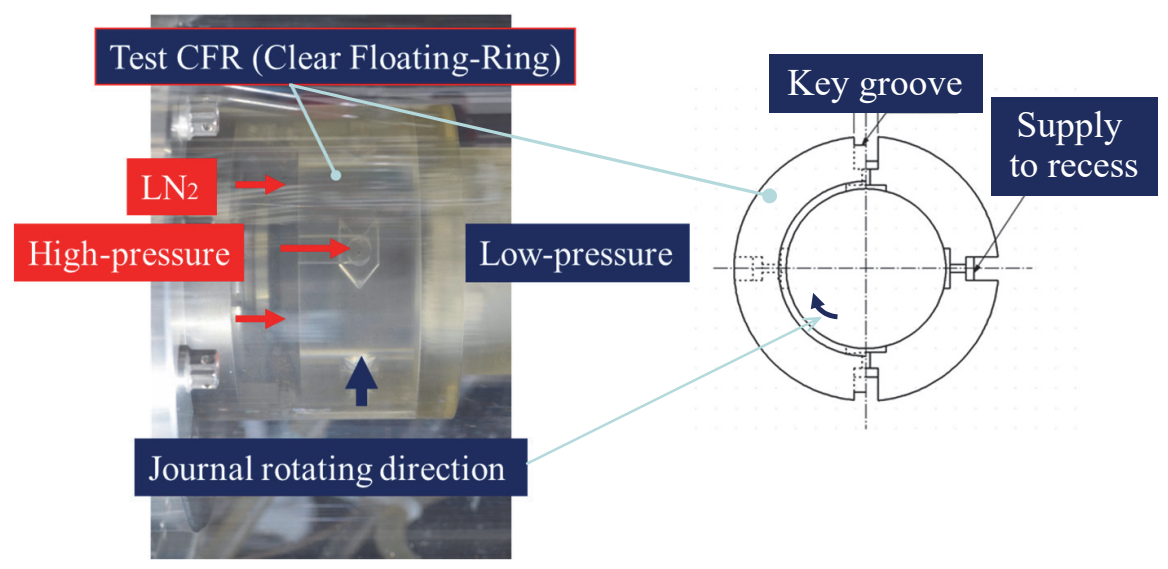

Fig. 3 Photograph of the test CFR (Type D) section [9] 
Type B

$\left(\theta_{s}=0 \mathrm{deg}\right.$.)

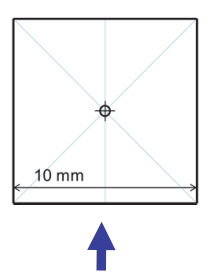

Type $\mathrm{F}$

$\left(\theta_{s}=45\right.$ deg. $)$

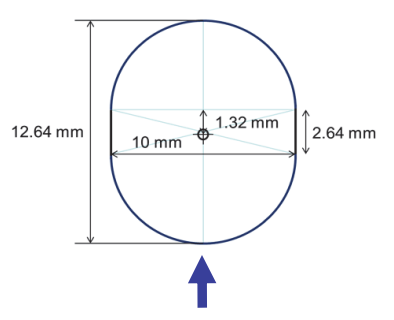

Type C

$(\theta s=-45$ deg.)

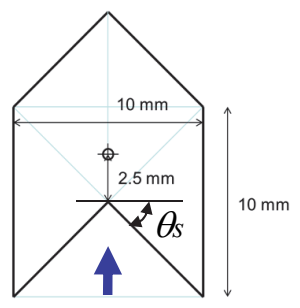

Type $\mathrm{G}$

$\left(\theta_{s}=-45\right.$ deg. $)$

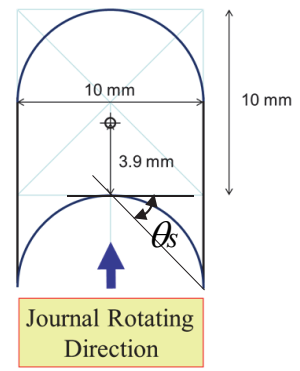

Type D ( $\theta_{s}=45$ deg. $)$

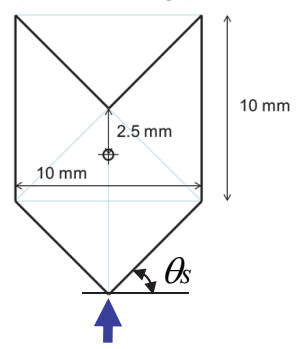

Type $\mathrm{K}$ $\left(\theta_{s}=45\right.$ deg. $)$

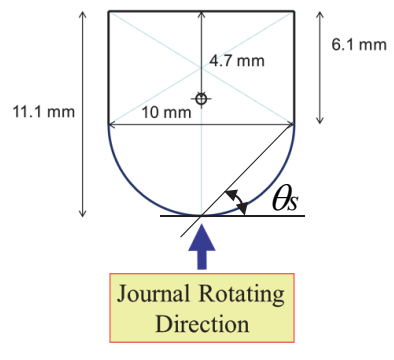

Type E

$\left(\theta_{s}=45\right.$ deg.)

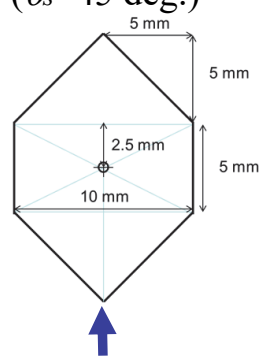

Type $\mathrm{M}$

$\left(\theta_{s}=0\right.$ deg. $)$

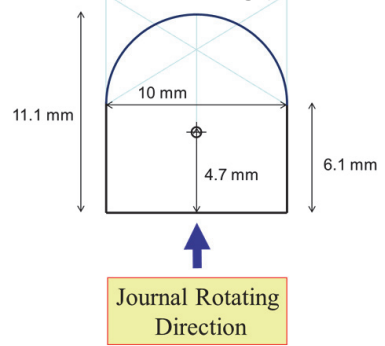

Fig. 4 Recess geometries of Types E, F, G, K and M

plane rhombus (Type E), the plane circle (Type F), the circular Young Leaf Mark (Type G), the dome (Type K) and the revise dome (Type M) geometries, as shown in Fig. 4. The geometry parameters of the test CFRs including the recess geometry, the static radial clearance $\left(C_{0}\right)$ in $\mathrm{LN}_{2}$ and the sweepback angle of the recess leading edge $\left(\theta_{s}\right)$ are listed in Tables 1 and 2 . The recess geometries of Types B, C, D and FR are also shown in Fig. 4 and listed in Table 2. The journal surface is coated with $\mathrm{Cr}_{2} \mathrm{O}_{3}$ plasma spray film so that its surface seems to be black.

Table 1 Geometry parameters of a test CFR

\begin{tabular}{l|c}
\hline Diameter of CFR, $d(\mathrm{~mm})$ & 40 \\
\hline Axial length of CFR, $L(\mathrm{~mm})$ & 30 \\
\hline Recess orifice diameter, $d o(\mathrm{~mm})$ & 1.0 \\
\hline Number of recesses, $\mathrm{Nr}$ & 4 \\
\hline Maximum axial length of recess, $\mathrm{Lr}(\mathrm{mm})$ & 10 \\
\hline Maximum recess depth, $h(\mathrm{~mm})$ & 1.0 \\
\hline Recess area ratio, $\mathrm{Ar}$ & 0.106 \\
\hline
\end{tabular}

\subsection{Test procedure}

The test CFRs were operated at a rotational speed of up to $40,000 \mathrm{rpm}$ using the cryogenic flow visualization test apparatus [10] at the JAXA Kakuda Space Center. Figure 5 shows a photograph of the test apparatus, which is constructed with a visualization section, a rotor support section and a compact electric motor. The rotor is supported by a pair of selflubricated ball bearings cooled by cryogenic liquid and driven by the electric motor connected with one end of the rotor. The cryogenic liquid is sealed by a face contact metal-bellows mechanical seal and the test CFR. The clear case of the test CFR is also made of polycarbonate and the outer case of the test apparatus in the test CFR section is composed of a transparent plastic, acrylic acid resin. The cavity between the clear case and the clear outer case is evacuated by a vacuum pump to create a heat insulation layer. The flow pattern in the CFR clearance was observed by three video cameras and a high-speed video camera installed in four radial directions, as shown in Fig. 5. Liquid nitrogen $\left(\mathrm{LN}_{2}\right)$ was supplied to the test CFR with a pressure of up to $1.7 \mathrm{MPa}$ to achieve a safe, easy operation. The main test conditions are listed in Table 3. Test conditions

Table 2 Recess geometries of test CFRs

\begin{tabular}{c|c|c|c}
\hline Type of CFR & $\begin{array}{c}\text { Static radial clearance, } \\
C_{0}(\mathrm{~mm})\end{array}$ & Recess geometry & $\begin{array}{c}\text { Mean recess sweepback angle, } \\
\theta_{s}(\text { degree })\end{array}$ \\
\hline Type E & 0.046 & Plane rhombus & 45 \\
\hline Type F & 0.042 & Plane circle & 45 \\
\hline Type G & 0.042 & Revise circular YLM & -45 \\
\hline Type K & 0.044 & Dome & 45 \\
\hline Type M & 0.046 & Revise dome & 0 \\
\hline Type B & 0.050 & Square & -45 \\
\hline Type C & 0.044 & Revise YLM & 45 \\
\hline Type D & 0.041 & Yung Leaf Mark (YLM) & - \\
\hline Type FR & 0.047 & None & \\
\hline
\end{tabular}




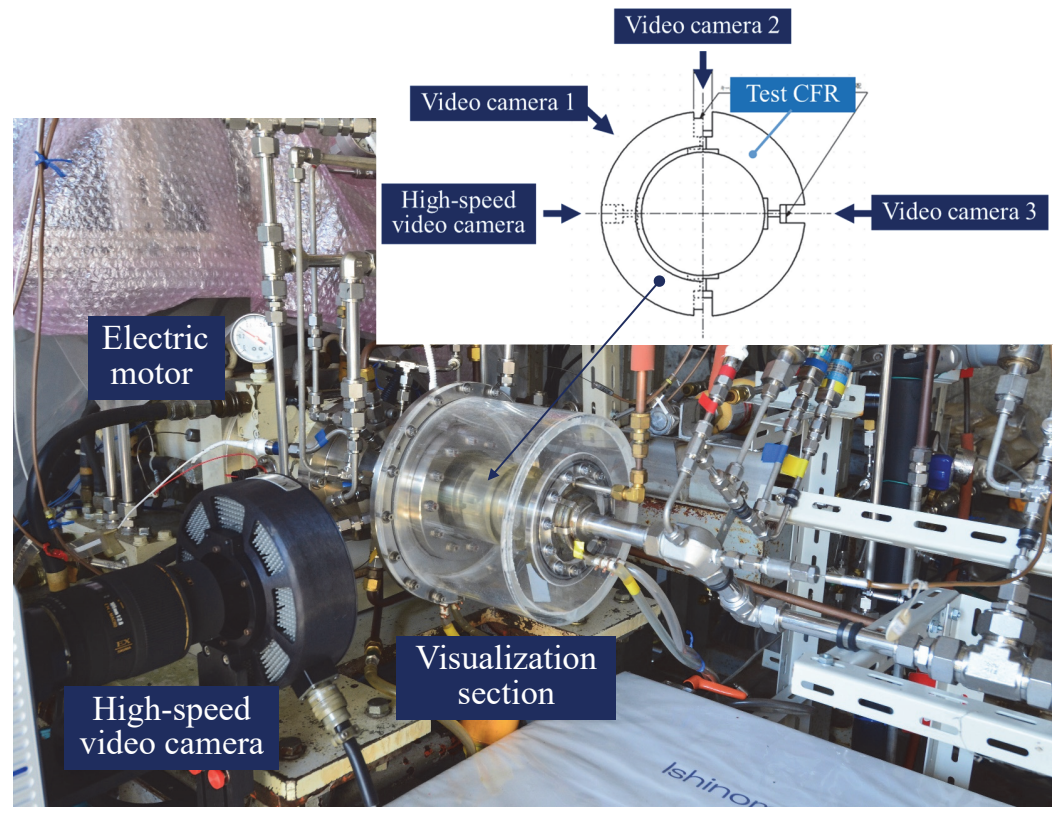

Fig. 5 Photograph of the test apparatus

Table 3 Main test conditions

\begin{tabular}{l|c}
\hline $\mathrm{LN}_{2}$ supply pressure, $P_{1}(\mathrm{MPa})$ & $0.7-1.7$ \\
\hline Pressure difference of $\mathrm{CFP}, \Delta P_{12}(\mathrm{MPa})$ & $0.6-1.6$ \\
\hline $\mathrm{LN}_{2}$ supply temperature, $T_{1}(\mathrm{~K})$ & $85-105$ \\
\hline $\mathrm{LN}_{2}$ supply flow rate, $Q(\ell / \mathrm{s})$ & $0.050-0.140$ \\
\hline Steady rotational speed, $N(\mathrm{rpm})$ & $20,000-40,000$ \\
\hline Sommerfeld number, $S$ & $0.46-1.03$ \\
\hline
\end{tabular}

such as $\mathrm{LN}_{2}$ supply pressure were established to operate the test CFR at over 40,000 rpm based on a previous study [9]. The static pressure and the fluid temperature were measured at major points in the test CFR and the apparatus. The pressure fluctuations upstream and downstream of the CFR were also measured by a piezoelectric pressure sensor. Volumetric flow rate of $\mathrm{LN}_{2}$ was measured by a turbine flowmeter installed in the supply line leading to the test CFR. In the experiment, the rotational speed firstly increases and then decreases by stages.

The flow coefficient $\left(C_{f}\right)$ defined by Eq. (1) is introduced to evaluate the flow condition in the CFR clearance.

$$
C_{f}=\frac{Q}{\pi d C_{0}} \sqrt{\frac{\rho_{\text {sat }}}{2 \Delta P_{12}}}
$$

Here, $\rho_{\text {sat }}$ is the saturated density of $\mathrm{LN}_{2}$ at the upstream temperature $\left(T_{1}\right)$. Thus, the flow coefficient expresses the ratio of the axial flow speed at the outlet of the CFR clearance based on the measured volumetric flow rate $(Q)$ to the axial flow speed of saturated $\mathrm{LN}_{2}$ calculated from the pressure difference of the CFR $\left(\Delta P_{12}\right)$. The value of $C_{f}$ is considered to be an index to evaluate a synergy effect of the inlet and outlet losses, and the two-phase flow on the flow condition through the clearance $[8,9]$. The cavitation area ratio $(A c)$ obtained by Eq. (2) is also introduced to evaluate the two-phase flow condition in the CFR clearance.

$$
A c=\frac{4 a_{c}}{\pi d L}
$$

Here, $a_{c}$ is the cavitation cloud area within the clearance on the fourth of the CFR inner surface obtained from the snapshot of the video image captured by the video camera 1 [9]. The flow coefficient and the cavitation area ratio were obtained for various values of the cavitation number $\left(\sigma_{p s}\right)$ defined by Eq. (3).

$$
\sigma_{p s}=\frac{P_{1}-P_{\text {sat }}}{\Delta P_{12}+(1 / 2) \rho_{\text {sat }} V_{\theta}^{2}}
$$

Here, $P_{\text {sat }}$ is the saturated pressure at $T_{1}$, and $V_{\theta}$ is the circumferential velocity of the journal outer surface. Thus, the value of $\sigma_{p s}$ takes into account the pressure drop and the flow speed of saturated $\mathrm{LN}_{2}$ induced by the journal rotation through the CFR clearance [9].

\section{Experimental results}

Five test series were newly carried out in the present study. An example of the state and properties of liquid nitrogen obtained for Type F is listed in Table 4. Liquid nitrogen is found to be in the saturated condition downstream of the test CFR. The standard deviations of the measured static pressure and temperature were less than $1 \%$ of their average values under the steady rotating condition.

Figure 6 shows the variations of the $C_{f}$, the $A c$ and the $T_{1}$ vs the rotational speed obtained for Type E. Flow visualization images obtained at (a) to (d) denoted in the Fig. 6 are shown in Fig. 7. The variations and the images for Type F, Type G and Type $\mathrm{K}$ are also shown in Figs. 8 to 13. Since the journal surface is coated with $\mathrm{Cr}_{2} \mathrm{O}_{3}$ plasma spay film, it looks black in the image. When the cavitation occurs in the CFR clearance, it looks like a white cloud, i.e., a cavitation cloud, as shown in Figs. 7, 9, 11 and 13. According to the high-speed video image $(20,000$

Table 4 State and properties of liquid nitrogen $\left(\mathrm{LN}_{2}\right)$ obtained for Type $\mathrm{F}(N=37.3 \mathrm{krpm}, A c=0.867)$

\begin{tabular}{c|c|c}
\hline Location & Upstream & Downstream \\
\hline Pressure $(\mathrm{MPa})$ & 1.60 & 0.12 \\
\hline Temperature $(\mathrm{K})$ & 89.5 & 78.8 \\
\hline Density, $\rho\left(\mathrm{kg} / \mathrm{m}^{3}\right)$ & 753.4 & 802.0 \\
\hline Viscosity, $\mu(\mu \mathrm{Pa}-\mathrm{s})$ & 102.9 & 143.8 \\
\hline
\end{tabular}


fps), the flow pattern of the cavitation cloud is considered to be an unstable turbulent flow. Furthermore, it was confirmed that $\mathrm{LN}_{2}$ flowed out of the CFR clearance in the two-phase state independent of the rotational speed. The experimental results indicate that the value of $A c$ tends to increase with increasing rotational speed, and that the value of $C_{f}$ then tends to decrease with an increase in the rotational speed for each type of the CFR because of viscous frictional heating. However, a sudden change of $T_{1}$ seems to induce large variations of $A c$ and $C_{f}$ in the moderate speed operation independent of the CFR type.

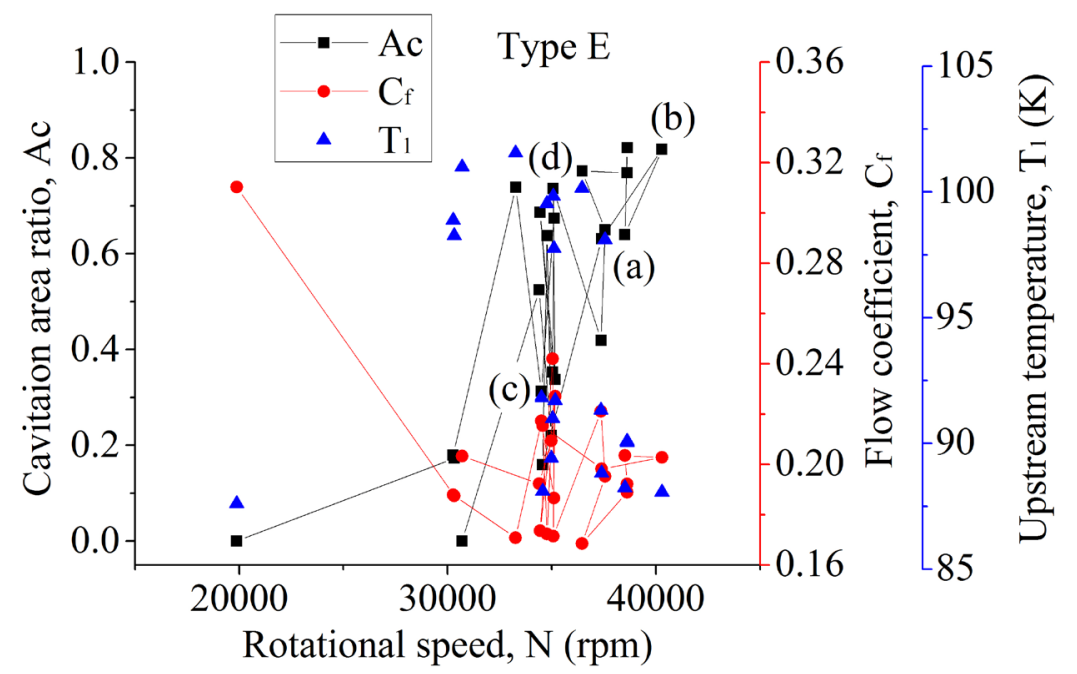

Fig. 6 Variations of the cavitation area ratio $(A c)$, the flow coefficient $\left(C_{f}\right)$ and the upstream temperature $\left(T_{1}\right)$ vs the rotational speed obtained for Type $\mathrm{E}$

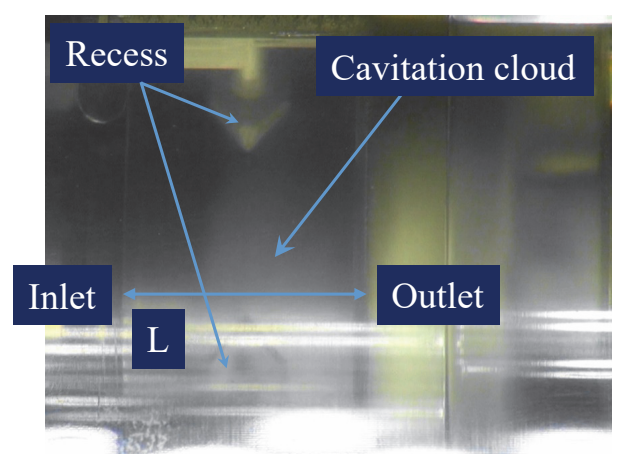

(a) $N=38.5 \mathrm{krpm}, T_{l}=88.2 \mathrm{~K}, \sigma_{p s}=0.328$, $C_{f}=0.213, A c=0.640$

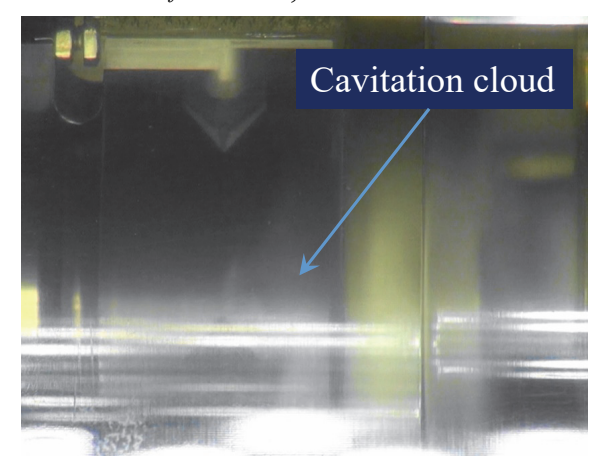

(c) $N=35.2 \mathrm{krpm}, T_{l}=91.7 \mathrm{~K}, \sigma_{p s}=0.345$, $C_{f}=0.238, A c=0.338$

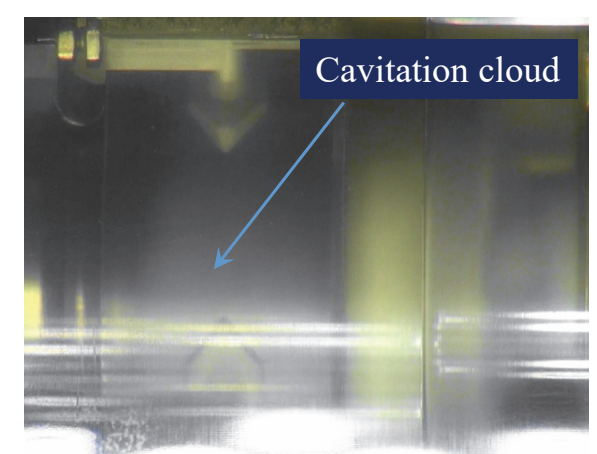

(b) $N=40.3 \mathrm{krpm}, T_{l}=88.1 \mathrm{~K}, \sigma_{p s}=0.311$, $C_{f}=0.212, A c=0.810$

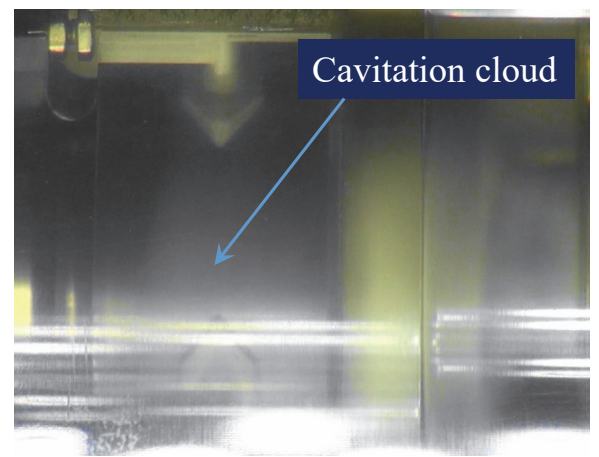

(d) $N=35.1 \mathrm{krpm}, T_{l}=99.8 \mathrm{~K}, \sigma_{p s}=0.217$, $C_{f}=0.179, A c=0.736$

Fig. 7 Visualization images obtained at the (a) to (d) denoted in Fig. 6 for Type E, captured by the video camera 1
(a) $N=38.5 \mathrm{krpm}, T_{1}=88.2 \mathrm{~K}, \sigma_{p s}=0.328, C_{f}=0.213, A c=0.640$
(b) $N=40.3 \mathrm{krpm}, T_{1}=88.1 \mathrm{~K}, \sigma_{p s}=0.311, C_{f}=0.212, A c=0.810$
(c) $N=35.2 \mathrm{krpm}, T_{1}=91.7 \mathrm{~K}, \sigma_{p s}=0.345, C_{f}=0.238, A c=0.338$
(d) $N=35.1 \mathrm{krpm}, T_{1}=99.8 \mathrm{~K}, \sigma_{p s}=0.217, C_{f}=0.179, A c=0.736$ 


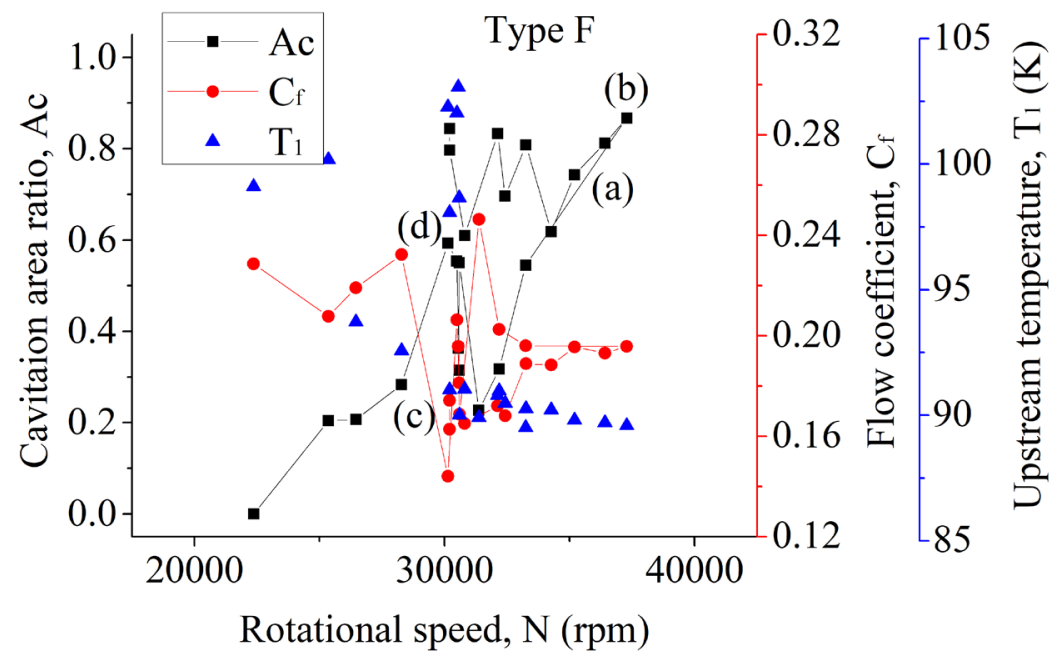

Fig. 8 Variations of the cavitation area ratio $(A c)$, the flow coefficient $\left(C_{f}\right)$ and the upstream temperature $\left(T_{1}\right)$ vs the rotational speed obtained for Type $\mathrm{F}$

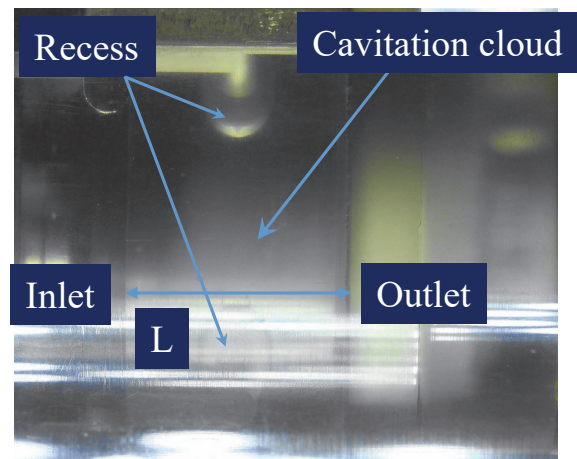

(a) $N=35.2 \mathrm{krpm}, T_{1}=89.7 \mathrm{~K}, \sigma_{p s}=0.354$, $C_{f}=0.196, A c=0.743$

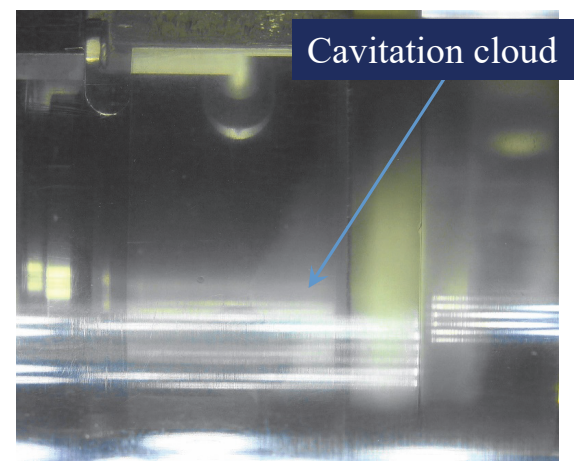

(c) $N=28.3 \mathrm{krpm}, T_{l}=92.6 \mathrm{~K}, \sigma_{p s}=0.408$, $C_{f}=0.232, A c=0.283$

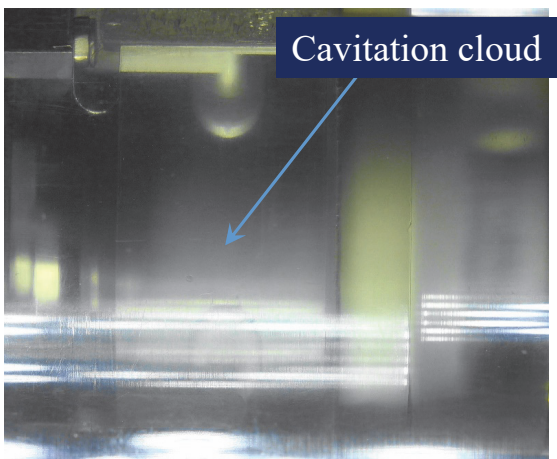

(b) $N=37.3 \mathrm{krpm}, T_{l}=89.5 \mathrm{~K}, \sigma_{p s}=0.333$, $C_{f}=0.196, A c=0.867$

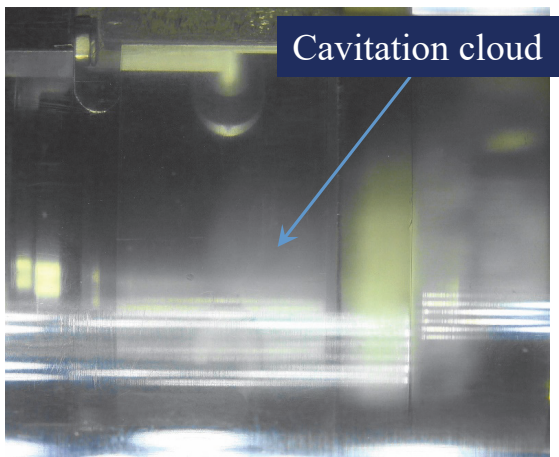

(d) $N=30.1 \mathrm{krpm}, T_{l}=102.3 \mathrm{~K}, \sigma_{p s}=0.251$, $C_{f}=0.144, A c=0.593$

Fig. 9 Visualization images obtained at the (a) to (d) denoted in Fig. 8 for Type F, captured by the video camera 1
(a) $N=35.2 \mathrm{krpm}, T_{1}=89.7 \mathrm{~K}, \sigma_{p s}=0.354, C_{f}=0.196, A c=0.743$
(b) $N=37.3 \mathrm{krpm}, T_{1}=89.5 \mathrm{~K}, \sigma_{p s}=0.333, C_{f}=0.196, A c=0.867$
(c) $N=28.3 \mathrm{krpm}, T_{1}=92.6 \mathrm{~K}, \sigma_{p s}=0.408, C_{f}=0.232, A c=0.283$
(d) $N=30.1 \mathrm{krpm}, T_{1}=102.3 \mathrm{~K}, \sigma_{p s}=0.251, C_{f}=0.144, A c=0.593$ 


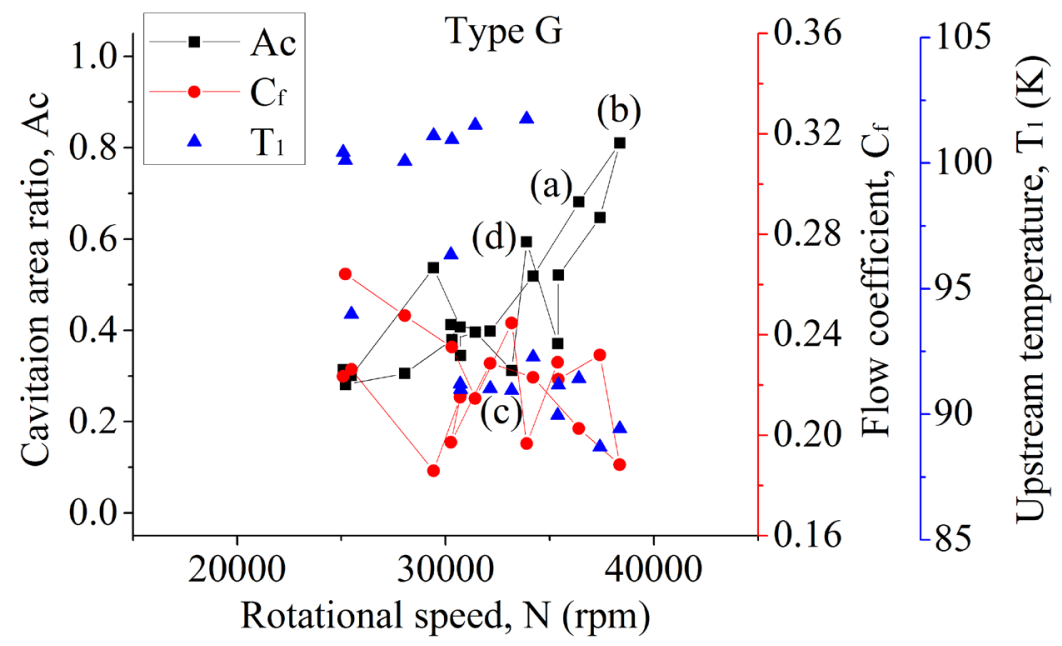

Fig. 10 Variations of the cavitation area ratio $(A c)$, the flow coefficient $\left(C_{f}\right)$ and the upstream temperature $\left(T_{1}\right)$ vs the rotational speed obtained for Type $\mathrm{G}$

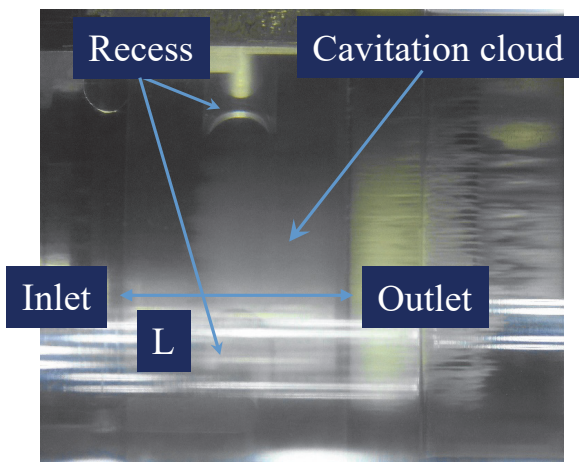

(a) $N=36.4 \mathrm{krpm}, T_{l}=90.3 \mathrm{~K}, \sigma_{p s}=0.330$, $C_{f}=0.206, A c=0.681$

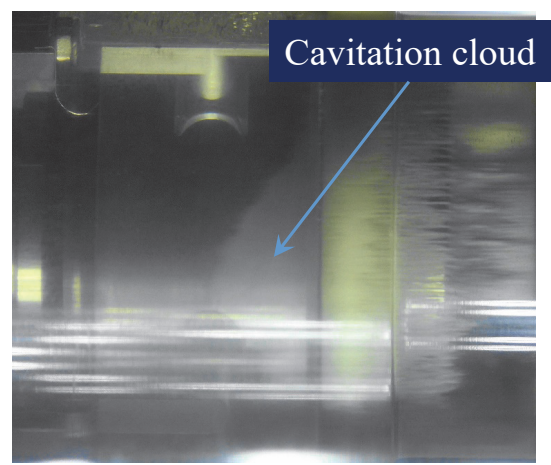

(c) $N=33.2 \mathrm{krpm}, T_{l}=90.4 \mathrm{~K}, \sigma_{p s}=0.371$, $C_{f}=0.245, A c=0.371$

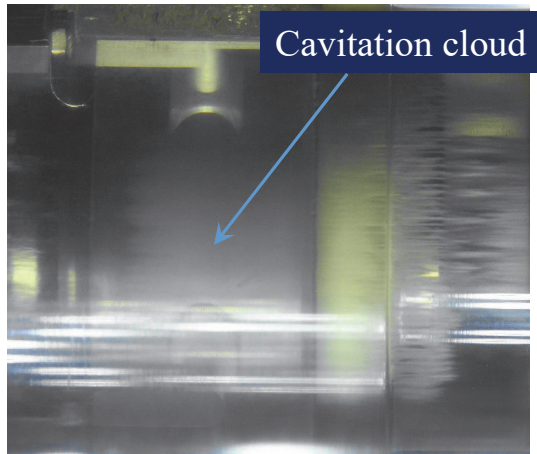

(b) $N=38.4 \mathrm{krpm}, T_{l}=88.6 \mathrm{~K}, \sigma_{p s}=0.322$, $C_{f}=0.200, A c=0.810$

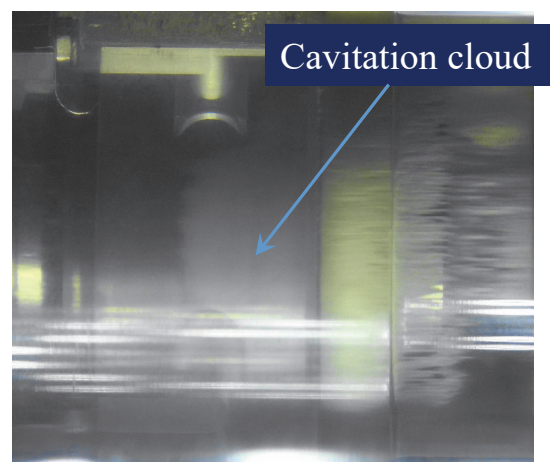

(d) $N=33.9 \mathrm{krpm}, T_{l}=101.9 \mathrm{~K}, \sigma_{p s}=0.221$, $C_{f}=0.197, A c=0.594$

Fig. 11 Visualization images obtained at the (a) to (d) denoted in Fig. 10 for Type G, captured by the video camera 1
(a) $N=36.4 \mathrm{krpm}, T_{1}=90.3 \mathrm{~K}, \sigma_{p s}=0.330, C_{f}=0.206, A c=0.681$
(b) $N=38.4 \mathrm{krpm}, T_{1}=88.6 \mathrm{~K}, \sigma_{p s}=0.322, C_{f}=0.200, A c=0.810$
(c) $N=33.2 \mathrm{krpm}, T_{1}=90.4 \mathrm{~K}, \sigma_{p s}=0.371, C_{f}=0.245, A c=0.371$
(d) $N=33.9 \mathrm{krpm}, T_{1}=101.9 \mathrm{~K}, \sigma_{p s}=0.221, C_{f}=0.197, A c=0.594$ 


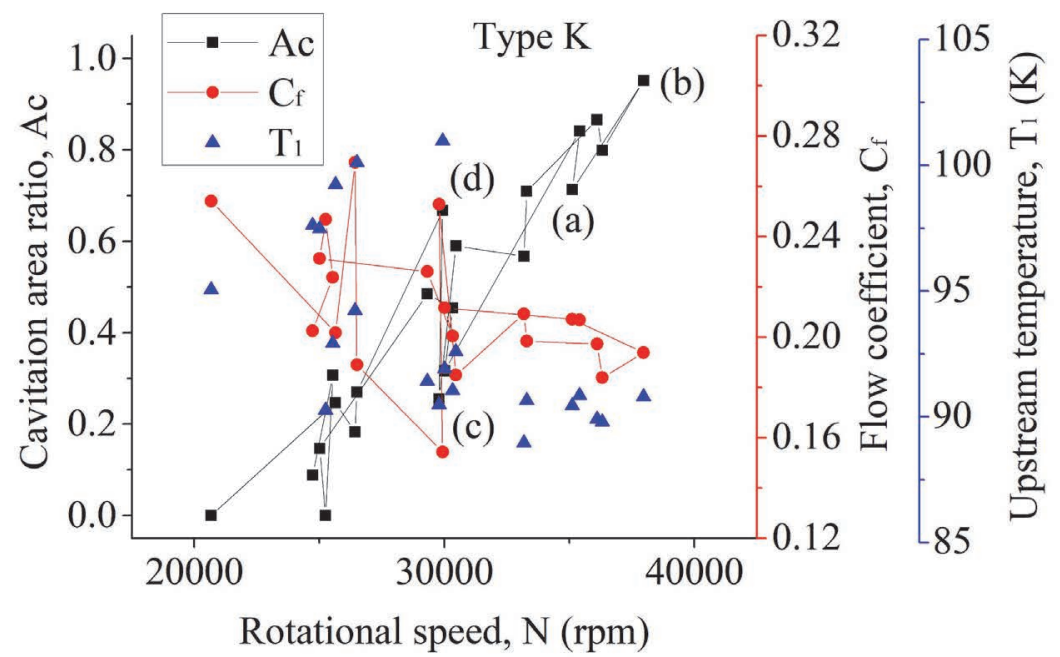

Fig. 12 Variations of the cavitation area ratio $(A c)$, the flow coefficient $\left(C_{f}\right)$ and the upstream temperature $\left(T_{1}\right)$ vs the rotational speed obtained for Type $\mathrm{K}$

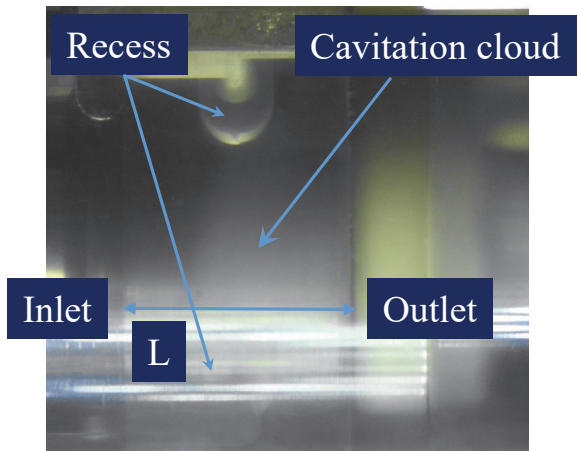

(a) $N=35.1 \mathrm{krpm}, T_{l}=90.4 \mathrm{~K}, \sigma_{p s}=0.330$, $C_{f}=0.207, A c=0.713$

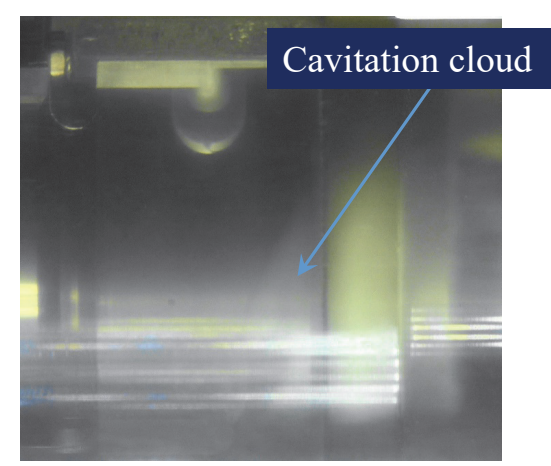

(c) $N=29.8 \mathrm{krpm}, T_{1}=90.5 \mathrm{~K}, \sigma_{p s}=0.356$, $C_{f}=0.253, A c=0.255$

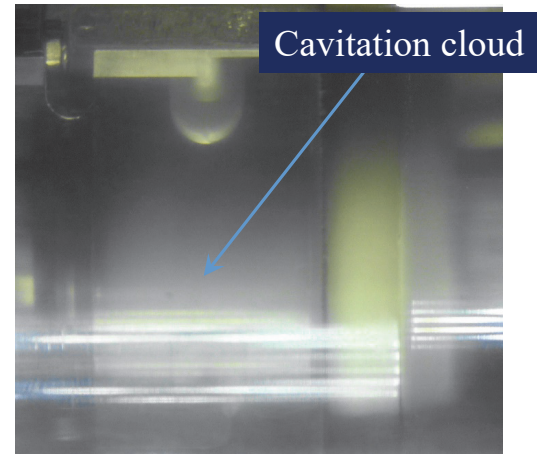

(b) $N=38.0 \mathrm{krpm}, T_{l}=90.8 \mathrm{~K}, \sigma_{p s}=0.299$, $C_{f}=0.194, A c=0.952$

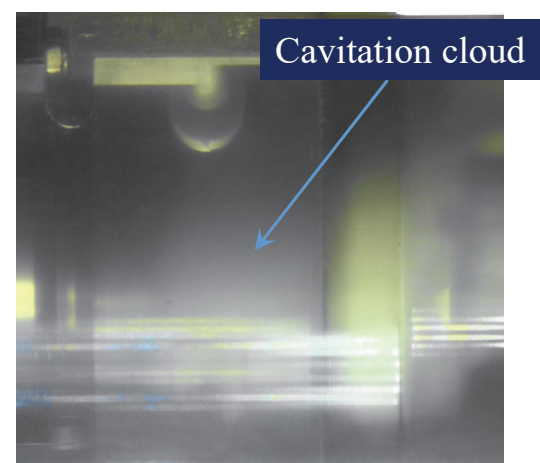

(d) $N=29.9 \mathrm{krpm}, T_{l}=101.0 \mathrm{~K}, \sigma_{p s}=0.245$, $C_{f}=0.154, A c=0.667$

Fig. 13 Visualization images obtained at the (a) to (d) denoted in Fig. 12 for Type K, captured by the video camera 1
(a) $N=35.1 \mathrm{krpm}, T_{1}=90.4 \mathrm{~K}, \sigma_{p s}=0.330, C_{f}=0.207, A c=0.713$
(b) $N=38.0 \mathrm{krpm}, T_{1}=90.8 \mathrm{~K}, \sigma_{p s}=0.299, C_{f}=0.194, A c=0.952$
(c) $N=29.8 \mathrm{krpm}, T_{1}=90.5 \mathrm{~K}, \sigma_{p s}=0.356, C_{f}=0.253, A c=0.255$
(d) $N=29.9 \mathrm{krpm}, T_{1}=101.0 \mathrm{~K}, \sigma_{p s}=0.245, C_{f}=0.154, A c=0.667$ 
(a)

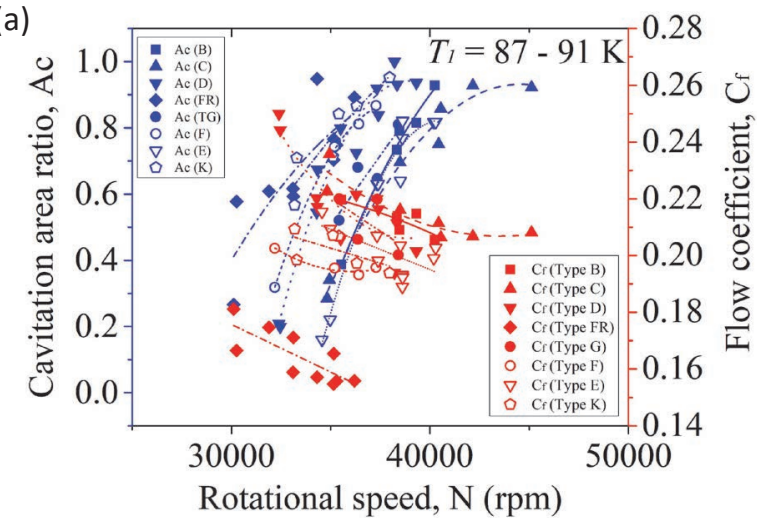

(b)

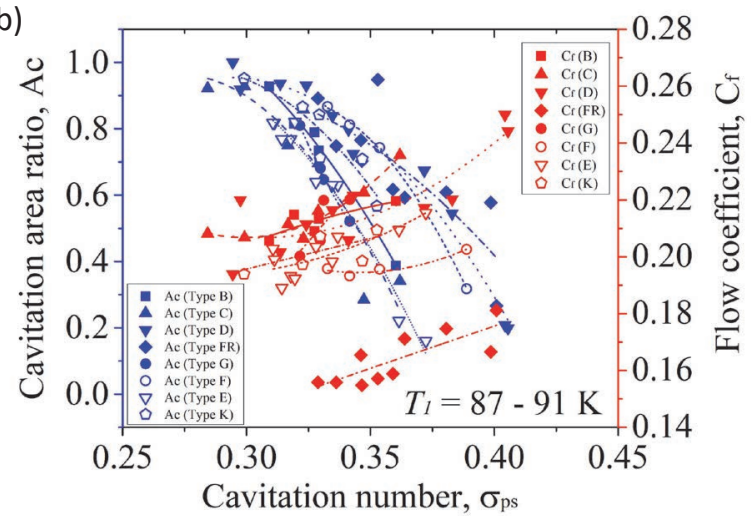

Fig. 14 Effect of the recess geometry on the cavitation area ratio $(A c)$ and the flow coefficient $\left(C_{f}\right)$ obtained for $T_{1}=87-91 \mathrm{~K}$ in the highrotational-speed operation

(a) Variations of the cavitation area ratio $(A c)$ and the flow coefficient $\left(C_{f}\right)$ vs the rotational speed

(b) Variations of the cavitation area ratio $(A c)$ and the flow coefficient $\left(C_{f}\right)$ vs the cavitation number $\left(\sigma_{p s}\right)$

\subsection{Steady state}

Firstly, the steady-state results obtained for $T_{1}=87$ to $91 \mathrm{~K}$ in the high-rotational-speed operation are described. The effects of the recess geometry on the values of $A c$ and $C_{f}$ are shown in Fig. 14. Figure 14 (a) shows the relationships between $A c$ and the rotational speed, and $C_{f}$ obtained for each type of the CFR. The relationships to the value of $\sigma_{p s}$ are also shown in Fig. 14 (b). The results of Types B, C, D and FR obtained in the previous study [9] are also plotted in Fig. 14. Each line represents a fitting curve. The value of $A c$ obtained for each type of CFR tends to increase with increasing rotational speed, i.e., decreasing $\sigma_{p s}$ for up to $A c=1$, while the value of $C_{f}$ tends to decrease. The values of $C_{f}$ obtained for Type FR without a recess are much smaller than those for the other types of the CFR because of no source flow from the recess. Comparison of $A c$ at the same value of $\sigma_{p s}$ indicates that the average values of Types $\mathrm{C}$ and $\mathrm{G}$ having $\theta_{s}=-45 \mathrm{deg}$. are smaller than those of the other types of CFR, and that the difference between them tends to be smaller as the cavitation number decreases. On the other hand, the average values of $C_{f}$ for Types $C$ and $G$ are larger than those of the other types of CFR in the high $\sigma_{p s}$ condition where the average value of $C_{f}$ obtained for Type B is located in the middle range between those of Types $C$ and $G$, and the other types of CFR. However, distinct differences among them are found to disappear in the low $\sigma_{p s}$ condition. These facts indicate that the flow characteristics in the CFR clearance was affected by the recess geometry even at the same value of $\sigma_{p s}$ in the relatively high $\sigma_{p s}$ condition.

Figure 15 shows the relationships between $A c$ and $C_{f}$ for each type of the CFR. Since two-phase flow of $\mathrm{LN}_{2}$ occurred at the clearance outlet independent of the rotational speed, the $C_{f}$ showed a considerably low value even if $A c=0$ [9]. The values of $C_{f}$ basically tend to decrease with the increase in $A c$. The $C_{f}$ values obtained for $T_{1}=87$ to $91 \mathrm{~K}$ in the high-rotationalspeed operation are plotted against the $A c$ values for each type of the CFR in Fig. 15. Each solid line represents a fitting curve. According to the fitting curves, the value of $C_{f}$ obtained for each type of CFR tends to decrease with increasing $A c$, and the $C_{f}$ value of Type FR without the recess is confirmed to be much smaller than those of the CFRs with the recess independent of the $A c$ value. Since the sonic speed of the cavitaing flow drastically decreases, the cavitating flow is considered to be choked at the clearance outlet. Therefore, the flow coefficient $\left(C_{f}\right)$ is denoted by Eq. (4).

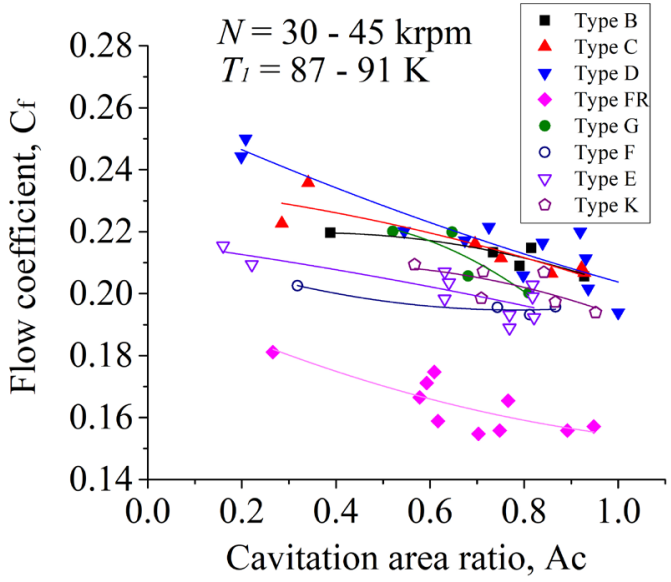

Fig. 15 Variations of the flow coefficient $\left(C_{f}\right)$ vs the cavitation area ratio $(A c)$ obtained for $T_{1}=87-91 \mathrm{~K}$ in the highrotational-speed operation

$$
C_{f}=\frac{\rho_{m} a_{m}}{\rho_{0}} \sqrt{\frac{\rho_{\text {sat }}}{2 \Delta P_{12}}}
$$

Here, $\rho_{m}$ is the mixture density of vapor and liquid twophase flow at the clearance outlet, $a_{m}$ is the sonic speed of the cavitating flow at the outlet, and $\rho_{0}$ is the density of $\mathrm{LN}_{2}$ at the turbine flowmeter. When the isothermal process without the thermodynamic effect of cavitation is assumed, the values of $\rho_{m}$ and $a_{m}$ are obtained from a void fraction $(\alpha)$ of the cavitating flow at the clearance outlet by using Eqs. (5) and (6) [11]:

$$
\begin{aligned}
& \rho_{m}=\alpha \rho_{v}+(1-\alpha) \rho_{l} \\
& a_{m}=a_{v}\left[\kappa\left\{\alpha^{2}+\alpha(1-\alpha) \frac{\rho_{l}}{\rho_{v}}\right\}\right]^{-0.5}
\end{aligned}
$$

where $\rho_{v}$ and $\rho_{l}$ are nitrogen saturated densities of vapor and liquid phases at the clearance outlet, and $\kappa$ is the specific heat ratio of nitrogen. Thus, the value of $C_{f}$ can be considered to depend mainly on the void fraction and the saturated temperature $\left(T_{\text {out }}\right)$ or pressure of nitrogen at the outlet plane of the CFR clearance. Figure 16 shows the relationships between the void fraction and the sonic speed at the outlet and those between the $C_{f}$ value obtained for $\Delta P_{12}=1.5 \mathrm{MPa}$ and the outlet saturated temperature range of $T_{\text {out }}=78-86 \mathrm{~K}$ by using Eqs. 


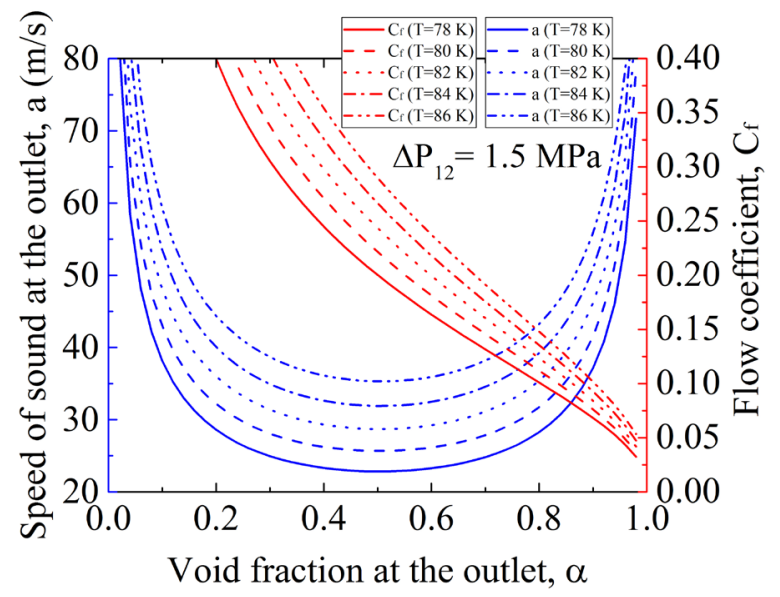

Fig. 16 Relationships between the void fraction and the sonic speed at the outlet plane of the clearance, and the $C_{f}$ value obtained for $\Delta P_{12}=1.5 \mathrm{MPa}$ and the outlet saturated temperature range of $T_{\text {out }}=78-86 \mathrm{~K}$ by using Eqs. (4) - (6) [9]

(4) - (6) based on the experimental results [9]. The average value of $C_{f}$ obtained for the CFRs with the recess is about 0.21 at $A c=0.8$ and that of Type FR is about 0.16 , as shown in Fig. 15. According to the results shown in Fig. 16, if the difference of $T_{\text {out }}$ between them is less than $2 \mathrm{~K}$, the $\alpha$ value of Type FR at the outlet is found to be about 0.1 larger than those of the CFRs with the recess. Furthermore, the maximum difference of $C_{f}$ between Type $\mathrm{C}$ and Type $\mathrm{F}$ near $\sigma_{p s}=0.36$ is found to be about $0.04(=0.24-0.20)$ in Fig. 14 (b), which indicates that the recess geometry difference caused an increase of about 0.063 in the void fraction at the clearance outlet.

\subsection{Transient state}

The influence of the sudden change of the upstream temperature $\left(T_{1}\right)$ of $\mathrm{LN}_{2}$ on the flow condition in the clearance of the CFR was investigated under the condition of a nearly constant rotational speed. As shown by (c) and (d) denoted in Figs. 6, 8, 10 and 12, a sudden rise in the upstream temperature $\left(\Delta T_{1}\right)$ occurred in the moderate speed operation independent of the CFR type, which induced a drop in the cavitation number $\left(\sigma_{p s}\right)$ and consequently induced a rise in the cavitation area ratio $(\triangle A c)$ and a drop in the flow coefficient $\left(\Delta C_{f}\right)$. Figure 17 shows visualization images obtained before and after the sudden rise in the upstream temperature $\left(\Delta T_{1}\right)$ for Type $M$. Figure 18 shows the effect of the sudden rise in the upstream temperature on the cavitation area ratio and the flow coefficient for each type of the CFR including Type M. Figure 18 (a) shows the relationships between $\Delta T_{1}$ normalized by the Stepanoff's factor B ( $\left.T^{*}\right)[12]$ and $\Delta A c$, and $\Delta C_{f}$ divided by the average $\left(C_{f m}\right)$ of those before and after $\Delta T_{1}$. The normalized $\Delta T_{1}^{*}$ is defined by Eq. (7):

$$
\Delta T_{1}^{*}=\frac{\Delta T_{1}}{T^{*}}=\Delta T_{1} \frac{\rho_{l} C_{p l}}{\rho_{v} L_{h}}
$$

where $\rho_{v}$ and $\rho_{l}$ are saturated densities of vapor and liquid phases, $C_{p l}$ is the specific heat at constant pressure, and $L_{h}$ is the latent heat at $T_{1}$ before the rise. The values of $\Delta A c$ and $\Delta C_{f} / C_{f m}$ are also plotted against the drop in the cavitation number $\left(\Delta \sigma_{p s}\right)$ induced by $\Delta T_{1}$ in Fig. 18 (b). Figure 18 shows that the values of $\Delta A c$ and $\Delta C_{f} / C_{f m}$ depend on the recess configuration including no recess. The sweepback angle of the recess leading edge $\left(\theta_{s}\right)$ shown in Fig. 4 is introduced to express the differences between test CFRs, i.e., $\theta_{s}=-45 \mathrm{deg}$. for Types $\mathrm{C}$ and $\mathrm{G}, \theta_{s}=0 \mathrm{deg}$. for Types $\mathrm{B}$ and $\mathrm{M}$, and $\theta_{s}=45 \mathrm{deg}$. for Types D, E, F and K. Each bold solid line represents a linear fitting curve obtained for the CFRs with $\theta_{s}=45 \mathrm{deg}$. Each bold dashed line represents that for the CFRs with $\theta_{s}=0$ deg., and each bold dotted line represents that for the CFRs with $\theta_{s}=-45 \mathrm{deg}$. Comparison between them at the same value of $\Delta T_{1}^{*}$ or $\Delta \sigma_{p s}$ indicates that both the $\Delta A c$ and $\Delta C_{f} / C_{f m}$ values obtained for the CFRs with $\theta_{s}=45 \mathrm{deg}$. are considerably larger than those for the CFRs with $\theta_{s}=-45$ degree. On the other hand, the values of $\Delta A c$ and $\Delta C_{f} / C_{f m}$ obtained for the CFRs with $\theta_{s}=0 \mathrm{deg}$. are located in the middle range between those for the CFRs with $\theta_{s}=45 \mathrm{deg}$. and the CFRs with $\theta_{s}=-45$ degree. Therefore, the pressure distributions within the clearances of the CFRs with $\theta_{s}=-45$ deg. can be considered to be higher than those of the CFRs with $\theta_{s}=45$ deg., which is basically correspondent with the steady-state results shown in Fig. 14.

\section{Discussion}

Five types of the CFRs with different recess geometries,

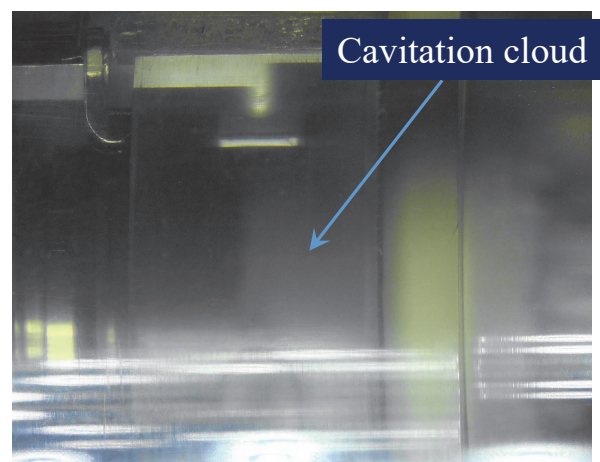

(b) $N=31.0 \mathrm{krpm}, T_{l}=102.5 \mathrm{~K}, \sigma_{p s}=0.226$, $C_{f}=0.186, A c=0.589$ (a) $N=31.2 \mathrm{krpm}, T_{l}=90.8 \mathrm{~K}, \sigma_{p s}=0.374$, $C_{f}=0.256, A c=0.227$

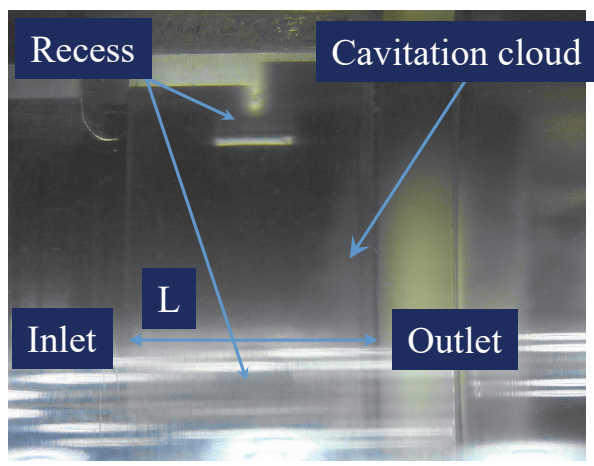
Fig. 17 Visualization images obtained b
captured by the video camera 1

(a) $N=31.2 \mathrm{krpm}, T_{1}=90.8 \mathrm{~K}, \sigma_{p s}=0.374, C_{f}=0.256, A c=0.227$

(b) $N=31.0 \mathrm{krpm}, T_{1}=102.5 \mathrm{~K}, \sigma_{p s}=0.226, C_{f}=0.186, A c=0.589$ 
(a)

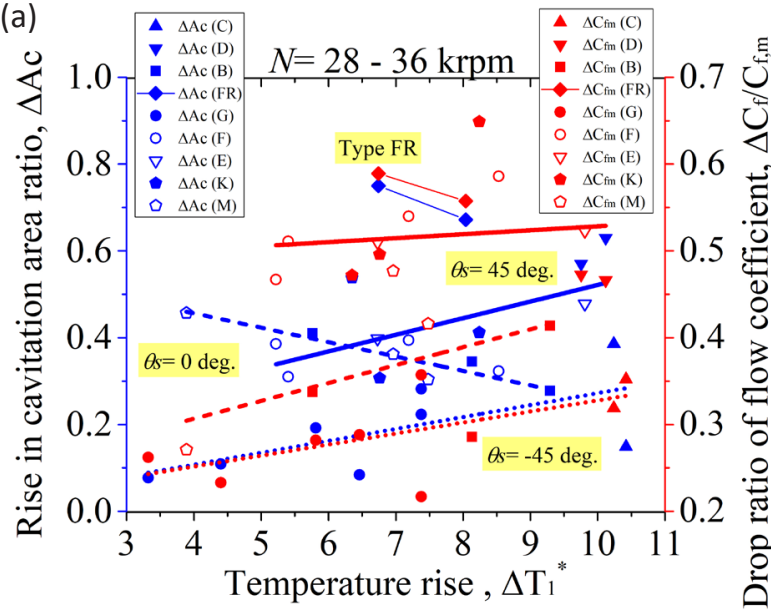

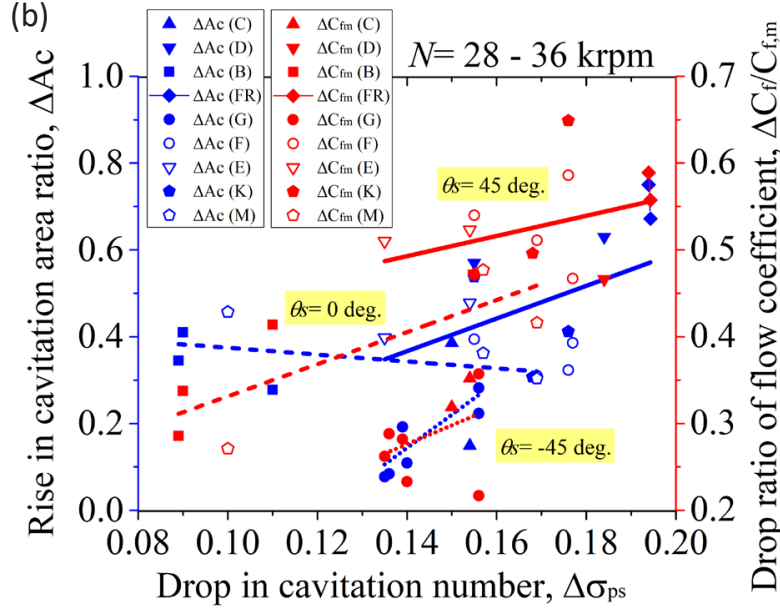

Fig. 18 Effect of the sudden rise in the upstream temperature $\left(\Delta T_{1}\right)$ on the cavitation area ratio and the flow coefficient

(a) Relationships between $\Delta T_{1}$ normalized by the Stepanoff's factor $\mathrm{B}\left(T^{*}\right)$ and $\Delta A c$, and $\Delta C_{f}$ divided by the average $\left(C_{f m}\right)$ of those before and after $\Delta T_{1}$

(b) Relationships between drop in the cavitation number $\left(\Delta \sigma_{p s}\right)$ induced by $\Delta T_{1}$ and $\Delta A c$, and $\Delta C_{f}$ divided by the average $\left(C_{f m}\right)$ of those before and after $\Delta T_{1}$

i.e., the plane rhombus, the plane circle, the revise circular Young Leaf Mark, the dome and the revise dome geometries, were newly operated at a rotational speed of up to $40,000 \mathrm{rpm}$ using liquid nitrogen as the working fluid to compare with the results obtained for four types of the CFRs presented in the previous study [9]. Figure 19 shows the relationships between the sweepback angle of the recess leading edge $\left(\theta_{s}\right)$ and the rise in the cavitation area ratio $(\Delta A c)$, and the drop ratio of the flow coefficient $\left(\Delta C_{f} / C_{f m}\right)$ induced by the sudden rise in the upstream temperature $\left(\Delta T_{1}\right)$. Data obtained in a narrow range of $\Delta \sigma_{p s}=0.13-0.17$ are plotted in Fig. 19 to focus on the effect of the sweepback angle of the recess leading edge. Each solid line represents a fitting curve. The average values of $\Delta A c$ and $\Delta C_{f} /$ $C_{f m}$ are found to increase monotonically with the increase in $\theta_{s}$ which demonstrates that the flow condition depends strongly on the sweepback angle of the recess leading edge.

The upstream boundary between the liquid phase and the cavitation cloud within the clearance may be considered to

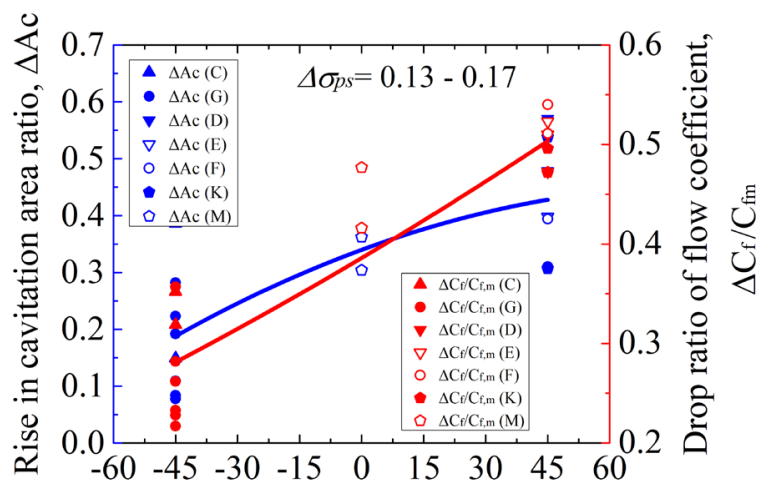

Sweepback angle of recess leading edge, $\theta_{\mathrm{s}}(\mathrm{deg})$

Fig. 19 Effect of the sweepback angle of the recess leading edge $\left(\theta_{s}\right)$ on the rise in the cavitation area ratio $(\triangle A c)$, and the drop ratio of the flow coefficient $\left(\Delta C_{f} / C_{f n}\right)$ induced by the sudden rise in the upstream temperature $\left(\Delta T_{1}\right)$, obtained for drop in the cavitation number of $\Delta \sigma_{p s}=0.13$ $-0.17$ present a kind of contour line of the highest saturated pressure. According to the visualization images in Figs. 7, 9, 11, 13 and 17, the rise in the cavitation area ratio induced by $\Delta T_{1}$ is found to be caused by the growth of the cavitation area from downstream to upstream of the recess area, which indicates that the value of $\triangle A c$ depends on the pumping effect of the recess. Therefore, the $\triangle A c$ values of the CFRs with $\theta_{s}=-45 \mathrm{deg}$. are basically smaller than those of the CFRs with $\theta_{s}=45 \mathrm{deg}$., which means that the recess pumping effect of the CFR with $\theta_{s}=-45 \mathrm{deg}$. is stronger than that of the CFR with $\theta_{s}=45$ degree. These results can be considered to demonstrate that the pumping effect of the recess induced by the interaction between the source flow from the recess and the rotating flow caused by the journal rotation is stronger in the CFR with $\theta_{s}=-45 \mathrm{deg}$. than in the CFR with $\theta_{s}$ $=45$ degree. In general, this feature would be easily predicted by the results obtained for the herringbone grooved journal bearings [13]. Therefore, it may be confirmed that the effects of the recess geometry on the flow characteristics of the cryogenic hybrid journal bearings are mainly caused by the influence of the $\theta_{s}$ value on the flow condition.

However, the strong pumping effect induced by the recess leading edge of the $\mathrm{HJB}$ with $\theta_{s}=-45 \mathrm{deg}$. may produce a large pressure fluctuation in the circumferential direction on the bearing inner surface, which seems to excite journal vibration for the cryogenic HJB. The average values of $\Delta H$ and $\Delta V$ obtained for over $60,000 \mathrm{rpm}$ in Fig. 2 are plotted against the sweepback angle of the recess leading edge in Fig. 20 [8]. An error bar of the average represents the standard deviation $( \pm \sigma)$, and the average rotational speed of each type is about $N=$ $64,000 \mathrm{rpm}$, respectively. Each line represents the fitting curve. The amplitudes of rotor vibration obtained for $N>60,000 \mathrm{rpm}$ are found to decrease monotonically with the increase in $\theta_{s}$, which indicates that the rotor vibration depends strongly on the sweepback angle of the recess leading edge in the highrotational-speed operation. Since a source flow from the recess interferes with the rotating flow induced by the journal rotation in the bearing clearance, $\theta_{s}=-45 \mathrm{deg}$. is considered to cause a stronger disturbance flow than that of $\theta_{s}=45 \mathrm{deg}$. in the highrotational-speed operation where the hydrodynamic effect is predominant. This may be one of the main reasons why the 


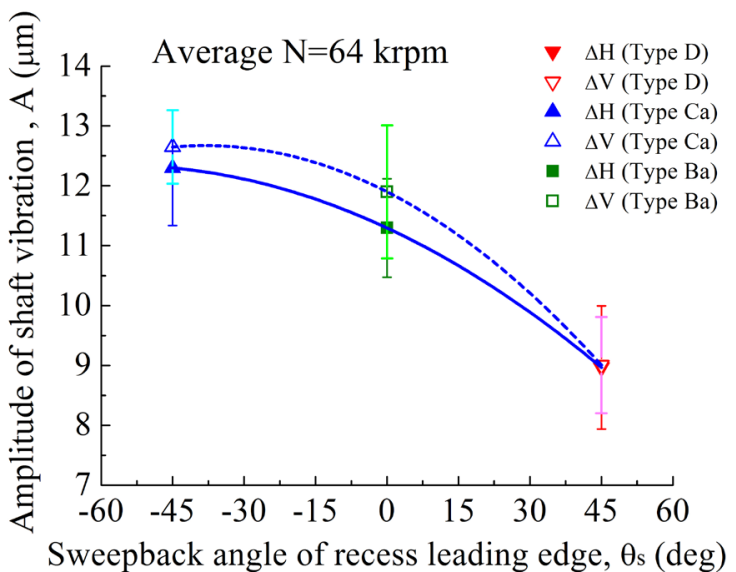

Fig. 20 Comparisons of the horizontal and vertical amplitudes $(\Delta H$ and $\Delta V$ ) of the rotor vibration for Types $\mathrm{D}, \mathrm{Ca}$ and $\mathrm{Ba}$ of HJBs in the high-rotational-speed operation [8]

dependence of the rotor vibration on the rotational speed was affected by the sweepback angle of the recess leading edge.

\section{Conclusions}

A flow visualization experiment in the clearance between a clear floating-ring (CFR) and a rotating journal was carried out in order to clarify the effects of the recess geometry on the flow characteristics. Five types of the CFRs with different recess geometries, i.e., the plane rhombus, the plane circle, the revise circular Young Leaf Mark, the dome and the revise dome geometries, were operated at a rotational speed of up to 40,000 rpm using liquid nitrogen as the working fluid to observe the interaction between source flow from the recess and rotating flow induced by the journal rotation in the clearance. The influence of the sweepback angle of the recess leading edge $\left(\theta_{s}\right)$ on the flow characteristics was investigated by the comparing flow coefficient $\left(C_{f}\right)$ and the cavitation cloud area ratio $(A c)$ obtained from the visual image.

Based on the experimental results obtained for nine types of the CFRs with different recess geometries, the dependence of the flow characteristics on the rotational speed was verified to be affected by the sweepback angle of the recess leading edge. The results obtained in the steady-state and the transient-state demonstrated that the pumping effect of the recess induced by the interaction between the source flow from the recess and the rotating flow caused by the journal rotation is stronger in the CFR with $\theta_{s}=-45 \mathrm{deg}$. than in the CFR with $\theta_{s}=45 \mathrm{deg}$. independent of the recess edge geometry.

Therefore, it may be considered that the effects of the recess geometry on the cryogenic HJBs are mainly caused by the influence of the sweepback angle of the recess leading edge on the flow condition in the high-rotational-speed operation where the hydrodynamic effect is predominant.

\section{Acknowledgments}

This work was supported by the Japan Society for the Promotion of Science under Grant-in-Aid for Scientific Research (C) 25420128. The authors would like to thank Takanori Sakashita for his cooperation in carrying out the experiments.

\section{References}

[1] Nosaka, M., Oike, M., Kikuchi, M., Kamijo, K. and Tajiri, M., "TriboCharacteristics of Self-Lubricating Ball Bearings for the LE-7 Liquid Hydrogen Rocket-Turbopump," Tribology Transactions, 36, 3, 1993, 432-442.

[2] Franchek, N. M. and Childs, D. W., “Experimental Test Results for Four High-Speed, High-Pressure, Orifice-Compensated Hybrid Bearings," ASME Journal of Tribology, 116, 1, 1994, 147-153.

[3] Reddecliff, J. M. and Vohr, J. H., "Hydrostatic Bearings for Cryogenic Rocket Engine Turbopumps," ASME Journal of Lubrication Technology, 91, 3, 1969, 557-575.

[4] Bickel, M., Leuchs, M., Lange, H., Nelis, M. and Bozet, J. L., “Ceramic Journal Bearings in Cryogenic Turbo-pumps," Proc. $9^{\text {th }}$ European Space Mechanisms \& Tribology Symposium, Liege, September 2001, 1-10.

[5] Ohta, T. and Ogata, H., "Application of Hydrostatic Bearings to $\mathrm{LH}_{2}$ Turbopump," Proc. $4^{\text {th }}$ International Conference on Launcher Technology, Liege, December 2002, 1-6.

[6] Oike, M., Kikuchi, M., Takada, S., Sudo, T. and Yoshida, M., "Effect of the Recess Aspect Ratio on Cryogenic Hybrid Journal Bearings," Proc. World Tribology Congress 2009 Kyoto, September 2009, 541.

[7] Oike, M., Kikuchi, M., Takada, S., Sudo, T. and Takano, T., "Robustness of Cryogenic Hybrid Journal Bearings," Tribology Online, 7, 3, 2012, 171-178.

[8] Oike, M., Kikuchi, M., Takada, S., Sudo, T. and Takano, T., "Influences of Journal Rotating Direction on Cryogenic Hybrid Journal Bearings," Tribology Online, 10, 2, 2015, 96-105.

[9] Oike, M., Kikuchi, M., Takada, S., Sudo, T. and Takano, T., "Study on Flow Characteristics of Cryogenic Hybrid Journal Bearings," Tribology Online, 11, 5, 2016, 583-593.

[10] Oike, M., Nosaka, M., Kikuchi, M. and Hasegawa, S., "Two-Phase Flow in Floating-Ring Seals for Cryogenic Turbopumps," Tribology Transactions, 42, 2, 1999, 273-281.

[11] Brennen, C. E., "Cavitation and Bubble Dynamics," Oxford University Press, New York, 1995.

[12] Stepanoff, A. J., "Cavitation Properties of Liquids," Journal of Engineering for Power, 86, 2, 1964, 195-199.

[13] Vohr, J. H. and Chow, C. Y., "Characteristics of HerringboneGrooved, Gas-Lubricated Journal Bearings," Journal of Basic Engineering, 87, 3, 1965, 568-576. 